\title{
Review
Strongyloides stercoralis infection in Ethiopia: systematic review and meta-analysis on prevalence and diagnostic methods

\author{
T. HAILU ${ }^{1, *}$, E. NIBRET ${ }^{2}$, A. AMOR ${ }^{3}$, A. MUNSHEA ${ }^{2}$ \\ 1Department of Medical Laboratory Science, College of Medicine and Health Sciences, Bahir Dar University, Bahir Dar, Ethiopia, \\ E-mail: tadessehailu89@gmail.com; ²Biology Department, Science College, Bahir Dar University, Bahir Dar, Ethiopia; \\ ${ }_{3}^{3}$ Mundo Sano Foundations, Institute of Health Carlos III, Madrid, Spain
}

Article info

Received April 28, 2020

Accepted August 12, 2020

\section{Summary}

Strongyloides stercoralis is a helminthic intestinal parasite that causes the disease strongyloidiasis. Its prevalence is high in tropics and sub-tropics due to poor sanitation and hygiene. However, its true prevalence is not well known in Ethiopia as most health institutions use low sensitive diagnostic methods. This review aimed to determine the pooled prevalence of $S$. stercoralis at country, and regional state levels. Papers published on S. stercoralis in Ethiopia from 2010 to 2020 were collected from PubMed, Google Scholar and Science direct databases and Addis Ababa repository. Identification, screening, checking the eligibility, and inclusion of the relevant literatures were done. Articles with S. stercoralis positive results from Ethiopian populations were included. Articles which focused on Strongyloides infection in foreigners, and other than stool samples were excluded. The pooled prevalence of $S$. stercoralis and heterogeneity between studies and across regions were computed. From the 43 articles, the overall prevalence of $S$. stercoralis in Ethiopia was $1.82 \%$. Across regions, relatively high prevalence of $S$. stercoralis (8.78 \%) was recorded in Addis Ababa city. High prevalence of $S$. stercoralis was found to be $44.02 \%$ with a combination of formol ether concentration, Baermann concentration, and molecular methods. Low prevalence of $0.26 \%, 0.31 \%$, and $1.20 \%$ was evidenced respectively with Kato-Katz, direct saline microscopy, and formol ether concentration methods. Using random effect analysis, the pooled prevalence of $S$. stercoralis in Ethiopia, across regions and across diagnostic methods was $2.1 \%$ (95 \% Cl: $1.20-3.60), 2.6 \%(95 \% \mathrm{Cl}: 0.80-8.20)$ and $3.7 \%$ (95\% Cl: $1.10-11.70)$, respectively. The heterogeneity was high $(P<0.001)$. This review revealed that Strongyloides infection is probably underreported and its prevalence could be higher than the reported in Ethiopia. Therefore, a revision of the best combination of diagnostic methods could be advisable as it gives better diagnostic results in routine diagnosis of Strongyloides infection in Ethiopia.

Keywords: Strongyloides infection; prevalence; diagnostic methods; Ethiopia

\section{Introduction}

The genus Strongyloides is one of the soil-transmitted helminths that infect humans worldwide (Olsen et al., 2009). Strongyloides stercoralis and $S$. fuelleborni are the only two species that infect humans. Strongyloides stercoralis infection is prevalent across many areas of tropics and subtropics (Schar et al., 2013), whereas most S. fuelleborni human infections are prevalent in Africa (Schad et al., 1989). Strongyloides infection is a common problem in communities with poor personal hygiene, poor environmental sanita-

\footnotetext{
$\overline{\text { * - corresponding author }}$
} 
tion and open defecation practicing areas (Abrescia et al., 2009). The detection of larvae in stool is the major identification stage of the parasite (Siddiqui et al., 2001). The direct saline microscopy (DSM) is a very simple and rapid diagnostic method (Nielsen et al., 1987); however, it has poor sensitivity in S. stercoralis detection (Requena-Méndez et al., 2013). This is due to the fact that low parasite load and irregular larval excretion (Montes et al., 2010), and chronic low-intensity S. stercoralis infection (Schar et al., 2013) limit the sensitivity of traditional methods. As a result, misdiagnosis and underreporting of $S$. stercoralis infection by DSM is a common phenomenon.

Although better detection rate of $S$. stercoralis is obtained using one of the following: Baermann concentration technique (BCT), stool culture, Polymerase Chain Reaction (PCR), or a combination of these methods (Campo-Polanco et al., 2018), their limitations to apply as a routine diagnostic method in Ethiopia is a big challenge. This situation forced the health institutions to employ DSM method for the diagnosis of Strongyloides infection. As a result, under diagnosis and underreporting of the true prevalence of $S$. stercoralis infection in Ethiopia is a major problem (Terefe et al., 2019). Thus, the aim of this systematic review and meta-analysis was to provide an overview of the prevalence of Strongyloides infection by country and regional label and by diagnostic methods used in Ethiopia.

\section{Materials and Methods}

The PubMed, Google Scholar, and Science direct databases and Addis Ababa University repository were searched for articles written in English during the year 2010 to 2020 containing the keywords: "Strongyloidiasis" AND "Ethiopia" OR "Strongyloides AND "Ethiopia" OR "Strongyloides stercoralis" AND "Ethiopia" OR "Soil-transmitted helminths" AND "Ethiopia". The electronic data search of studies was conducted from January to 30 June 2020. Identification, screening, checking the eligibility and the inclusion
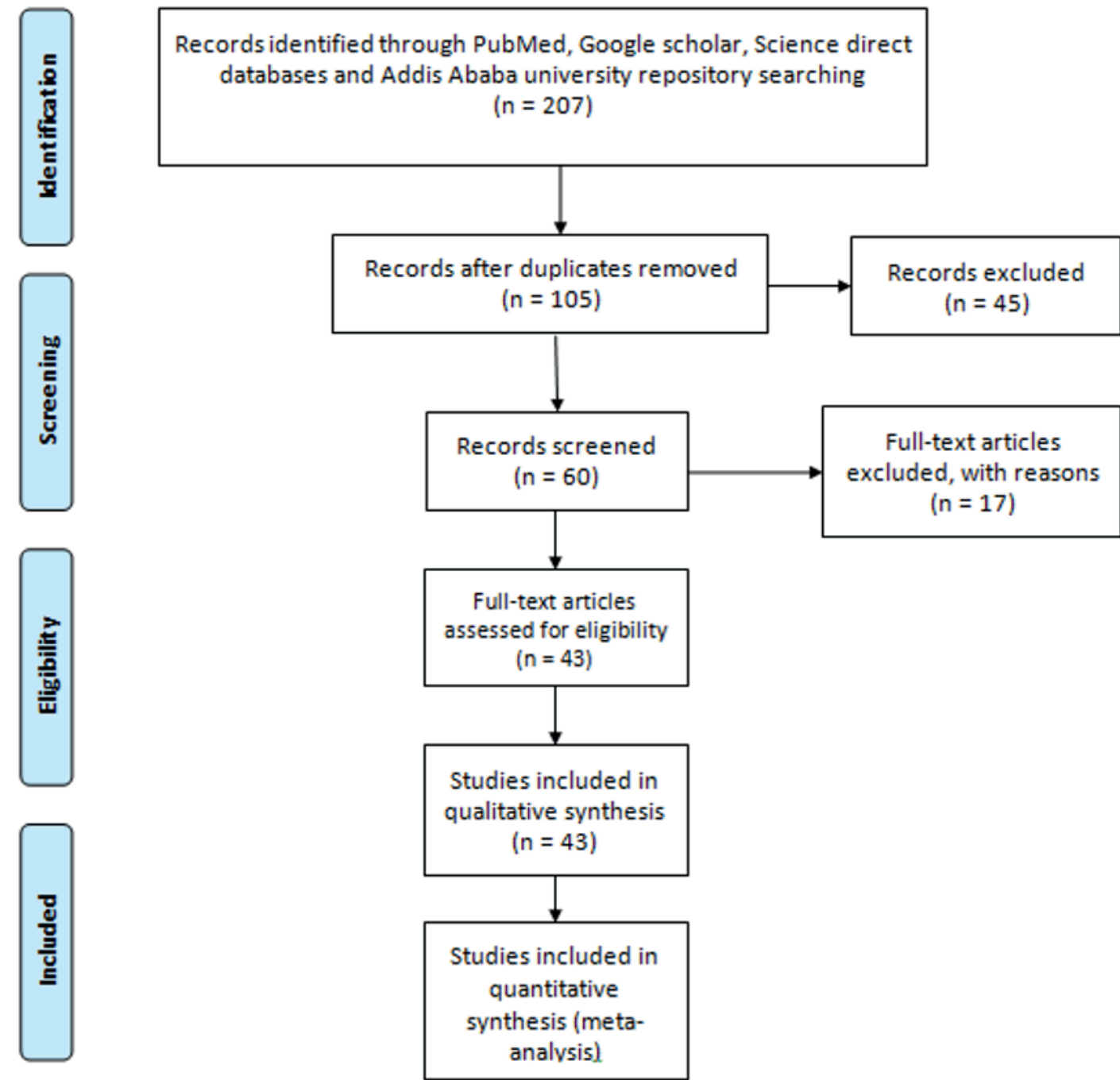

Fig. 1. Overview of search methods of the articles with inclusion and exclusion criteria. 
of the relevant literatures were done following the preferred reporting items for systematic reviews and meta-analyses (PRISMA) (Fig 1). Articles were first screened to remove duplication. And then the articles were also screened by reading titles and abstracts and initially excluded if they did not specifically refer to $S$. stercoralis or if they were review articles. Finally, the articles were further screened by reading the full articles an excluded if they did not investigate the prevalence of Strongyloides infection.

Inclusion criteria: All studies conducted in Ethiopian populations checking stool samples and diagnosed with DSM, Kato-Katz (KK), formol ether concentration techniques (FECT), BCT, culture, PCR or a combination these diagnostic techniques and got positive result for at least one individual among the study participants were included. Inclusion of literatures only from PubMed, Google Scholar, Science direct databases and Addis Ababa repository was the limitation. To minimize the risk of bias, publication bias assessment was done across studies.

Exclusion criteria: All articles dealing with Strongyloides infection in animals, soil, foreigners as study subjects in Ethiopia, non-stool samples, duplications, review articles, case studies, cohort studies and articles conducted before the year 2010 were excluded.

The data was extracted independently from each study and the pooled prevalence of $S$. stercoralis in Ethiopia, and across regions and by average prevalence by diagnostic method were also computed.

The meta-analysis was also performed using comprehensive meta-analysis 2.2 software (Biostat Inc., Englewood, NJ, USA). The pooled prevalence rate of $S$. stercoralis at country was calculated using a random-effect model at $95 \%$ confidence interval $(\mathrm{Cl})$. In the subgroup analysis, the pooled prevalence and forest plot of $S$. stercoralis in the regions and diagnostic methods was also calculated. Additionally, separate meta-analyses were performed to compare the effect of diagnostic methods in the detection of $S$. stercoralis. Heterogeneity between studies in region and across diagnostic methods was assessed using Cochran (Q)-value, $P$-value and $I^{2}$ and visual inspection of the funnel plot. The level of statistical significance for all tests was set at $P<0.05$. Publication bias was checked by funnel plot.

\section{Results}

A total of 207 studies identified from PubMed, Google scholar, Science direct databases and Addis Ababa University repository. Forty three studies were screened and recorded after duplications removed. Finally, 43 studies were eligible after full text assessment and included in qualitative analysis (Fig 1).

Prevalence of Strongyloides stercoralis

A total of 43 studies having $S$. stercoralis reports which full-filled the inclusion criteria and a total of 78,959 study participants were involved. The overall prevalence of $S$. stercoralis among study participants was $1.82 \%$ [1437/78959] (Table 1).

A relatively high prevalence $(55.68 \%)$ of $S$. stercoralis infection was recorded among participants age greater than five years (Aramendia et al., 2020) followed by $(20.71 \%)$ in schoolchildren of rural highlands of Amhara Regional State (Amor et al., 2016), $(20.0 \%)$ in SNNPR schoolchildren (Eriso F, 2014), (15.05\%) of schoolchildren in the Amhara Regional State (Hailu et al., 2020), and $(12.25 \%)$ in patients of health institution of Addis Ababa City (Hailegebriel et al., 2017) among studies conducted in Ethiopia (Table 1).

A very low prevalence of $S$. stercoralis; $(0.21 \%)$ in a community children (King et al., 2013), and $0.24 \%$ in patients of Amhara Regional State (Abate et al., 2013), $0.26 \%$ in schoolchildren of Tigray Regional State (Legese et al., 2010), and (0.26 \%) in HIV cases in Oromia Regional State (Admasu H, 2013), and $0.29 \%$ in patients (Ramose et al., 2014) was obtained from studies conducted in the country (Table 1).

In this review, the lowest prevalence of Strongyloides infection reported from a single study was $0.21 \%$ by FECT (King et al., 2013), followed by $0.24 \%$ by combination of DSM and FECT (Abate et al., 2013), $0.26 \%$ by KK (Leegese et al., 2010) and by combining DSM and FECT (Adamu et al., 2013), and $0.27 \%$ by DSM and FECT combination (Mengist et al., 2017) (Table 1).

Regarding regional reports relatively high prevalence of $S$. stercoralis $55.68 \%$ (Aramendia et al., 2020) and $20.21 \%$ (Amor et al., 2016), was reported using a combination of diagnostic methods in Amhara Regional State followed by $20.0 \%$ among Schoolchildren in SNNPR (Eriso H, 2014), and $12.25 \%$ among patients in Addis Ababa (Hailegebriel et al., 2017) (Table 1).

Among studies used single diagnostic methods, high prevalence $(20.0 \%)$ of S. stercoralis was recorded by BCT among schoolchildren in SNNPR (Eriso F, 2014) followed by $3.59 \%$ S. stercoralis prevalence by FECT in HIV cases in the Amhara Regional State (Eshetu T, 2017) and $3.13 \%$ prevalence by DSM among patients in Amhara Regional State (Huruy et al., 2011).

Using random effect analysis, the pooled prevalence of $S$. stercoralis in Ethiopia was $2.1 \%(95 \% \mathrm{Cl}: 1.20-3.60)$. The heterogeneity was high $\left(Q=4264.8, I^{2}=99.0 \%, P<0.001\right)$ (Fig 2).

The studies were distributed symmetrically about the combined effect size that showed the absence of publication bias (Fig 3 ).

From 43 studies, 16 (37.21\%) were conducted in Amhara regional state followed by $15(34.88 \%)$ in SNNPR. The number of participants was high 58,917 (74.62 \%) and 9,076 (11.49\%) in the SNNPR and the Tigray Regional State, respectively. The pooled prevalence of $S$. stercoralis was relatively high in the Addis Ababa City $(8.78 \%)$ followed by $(8.54 \%)$ in the Amhara Regional State among regions. Low prevalence $S$. tercoralis infection among regions was recorded in Tigray Regional State $(0.67 \%)$ followed by $(0.93 \%)$ in SNNPR (Table 2).

Using random effect analysis, the pooled prevalence of $S$. stercoralis across the regions was $2.6 \%(95 \% \mathrm{Cl}: 0.80-8.20)$. The 


\begin{tabular}{|c|c|c|c|c|c|c|c|c|}
\hline № & First Authors & $\begin{array}{l}\text { Year of } \\
\text { Pub }\end{array}$ & Region & $\begin{array}{l}\text { Participant } \\
\text { history }\end{array}$ & $\begin{array}{l}\text { Sample } \\
\text { size }\end{array}$ & $\begin{array}{l}\text { № SS } \\
\text { cases }\end{array}$ & Prevalence $(95 \% \mathrm{Cl})$ & Diagnostic method \\
\hline 1 & Hailu T & 2020 & Amhara & Sch & 844 & 127 & $15.05[12.74-17.68]$ & FECT,STST,BCT,APC \\
\hline 2 & Aramendia AA & 2020 & Amhara & $>5$ years & 792 & 441 & $55.68[52.14-59.17]$ & FECT,BCT,PCR \\
\hline 3 & Getaneh F & 2020 & Amhara & Patient & 67 & 2 & $3.0[0.82-10.25$ & DSM, KK \\
\hline 4 & Kuti KA & 2020 & Oromia & $\mathrm{FH}$ & 198 & 8 & $4.04[2.06-7.77]$ & DSM, FECT \\
\hline 5 & Tsegay B & 2020 & SNNPR & Children & 622 & 12 & $1.93[1.11-3.34]$ & DSM,FECT \\
\hline 6 & Menjetta T & 2019 & SNNPR & UN/student & 13,679 & 41 & $0.30[0.22-0.41]$ & DSM \\
\hline 7 & Gemech A & 2019 & SNNPR & Prisoner & 320 & 18 & 5.63 [3.59-8.72] & DSM, FECT \\
\hline 8 & Alemu G & 2019 & SNNPR & Sch & 351 & 7 & $1.99[0.97-0.41]$ & DSM, FECT \\
\hline 9 & Alemu G & 2018 & SNNPR & HIV & 220 & 4 & $1.82[0.71-4.58]$ & DSM, FECT \\
\hline 10 & Gebretsadik D & 2018 & Amhara & HIV & 223 & 1 & $0.45[0.02-2.86]$ & DSM, FECT \\
\hline 11 & Hailegebriel T & 2018 & Amhara & Sch & 382 & 5 & $1.31[0.48-3.21$ & FECT \\
\hline 12 & Teklmariam D & 2018 & Oromia & Sch & 280 & 4 & $1.43[0.46-3.87]$ & FECT,KK \\
\hline 13 & Mengist HM & 2017 & Oromia & Pregnant & 372 & 1 & $0.27[0.01-1.73]$ & DSM,FECT \\
\hline 14 & Eshetu T & 2017 & Amhara & HIV & 223 & 8 & $3.59[1.68-7.21]$ & FECT \\
\hline 15 & Feleke DG & 2017 & Tigray & Patient & 7,663 & 47 & $0.61[0.45-0.82]$ & DSM,FECT \\
\hline 16 & Alemu M & 2017 & Tigray & Patient & 427 & 8 & $1.87[0.87-3.80]$ & DSM,KK \\
\hline 17 & Hailegebriel T & 2017 & $\mathrm{AA}$ & Patient & 351 & 43 & $12.25[9.22-16.09]$ & $\begin{array}{l}\text { DSM,FECT, BCT } \\
\text { Culture }\end{array}$ \\
\hline 18 & Abdi $M$ & 2017 & Amhara & Sch & 408 & 3 & $0.74[0.25-2.15]$ & FECT \\
\hline 19 & Derso A & 2016 & Amhara & Pregnant & 348 & 6 & $1.72[0.79-3.70]$ & FECT \\
\hline 20 & Amor A & 2016 & Amhara & Sch & 396 & 82 & 20.71 [17.01-24.97] & FECT,BCT, PCR \\
\hline 21 & Shimlis T & 2016 & SNNPR & HIV & 491 & 22 & $4.48[2.90-6.81]$ & DSM,FECT \\
\hline 22 & Shiferaw MB & 2015 & Amhara & Patient & 464 & 5 & $1.08[0.40-2.65]$ & DSM,FECT \\
\hline 23 & Aleka Y & 2015 & Amhara & Patient & 277 & 1 & $0.36[0.06-2.01]$ & DSM,FECT \\
\hline 24 & Gedle D & 2015 & SNNPR & HIV & 305 & 5 & $1.64[0.70-3.78]$ & DSM, FECT \\
\hline 25 & Ramos JM & 2014 & SNNPR & Patient & 32,191 & 92 & $0.29[0.24-0.35]$ & DSM \\
\hline 26 & Mekonnen B & 2014 & $\mathrm{AA}$ & St/dweller & 355 & 19 & $5.35[3.45-8.20]$ & DSM, FECT, KK \\
\hline 27 & Mamo H & 2014 & Amhara & Prisoner & 236 & 6 & $2.54[1.10-5.71]$ & DSM,FECT \\
\hline 28 & Eriso F & 2014 & SNNPR & Sch & 710 & 142 & $20.0[17.16-23.17]$ & $\mathrm{BCT}$ \\
\hline 29 & Mahmud MA & 2013 & Tigray & Sch & 600 & 5 & $0.83[0.31-2.05]$ & DSM,FECT,KK \\
\hline 30 & Adamu H & 2013 & Oromia & HIV & 378 & 1 & $0.26[0.01-1.69]$ & DSM,FECT \\
\hline 31 & Bayessa C & 2013 & SNNPR & Patient & 6,342 & 73 & $1.15[0.92-1.44]$ & DSM, FECT \\
\hline 32 & Abera B & 2013 & Amhara & Sch & 778 & 27 & $3.47[2.40-5.00]$ & FECT, KK \\
\hline 33 & Zeynudin A & 2013 & Oromia & HIV & 91 & 6 & $6.59[3.05-13.64]$ & DSM,FECT \\
\hline 34 & Abate A & 2013 & Amhara & Patient & 410 & 1 & $0.24[0.04-1.36]$ & DSM, FECT \\
\hline 35 & King JD & 2013 & Amhara & Children & 2,338 & 5 & $0.21[0.09-0.49]$ & FECT \\
\hline 36 & Fekadu S & 2013 & SNNPR & HIV & 343 & 12 & $3.50[2.01-6.02]$ & DSM, FECT \\
\hline 37 & Teklemariam Z & 2013 & Harari & HIV & 371 & 15 & $4.04[2.46-6.56]$ & DSM,FECT \\
\hline 38 & Wogayehu T & 2013 & SNNPR & All age & 858 & 51 & $5.94[4.55-7.73]$ & DSM,FECT \\
\hline
\end{tabular}




\begin{tabular}{lllllllll}
39 & Huruy K & 2011 & Amhara & Patient & 384 & 12 & $3.13[1.80-5.39]$ & DSM \\
40 & Legese L & 2010 & Tigray & Sch & 386 & 1 & $0.26[0.05-1.45]$ & KK \\
41 & Nyantekyi LA & 2010 & SNNPR & Children & 288 & 2 & $0.69[0.19-2.49]$ & FECT, KK \\
42 & Getaneh A & 2010 & SNNPR & HIV & 384 & 27 & $7.03[4.88-10.04]$ & DSM, FECT, BCT \\
43 & Belyhun Y & 2010 & SNNPR & Kid+ Mother & 1,813 & 39 & $2.15[1.58-2.93]$ & FECT \\
\hline & Total & & & & 78,959 & 1,437 & $1.82[1.73-1.92]$ & \\
\hline
\end{tabular}

*AA = Addis Ababa, SNNPR = Southern Nations, Nationalities Peoples' Region, Sch = School children, FH = Food handler, HIV = Human Immunodeficiency Virus, St = Street, SS

= Strongyloides stercoralis, № $=$ Number, Pub $=$ Publication, UN = University

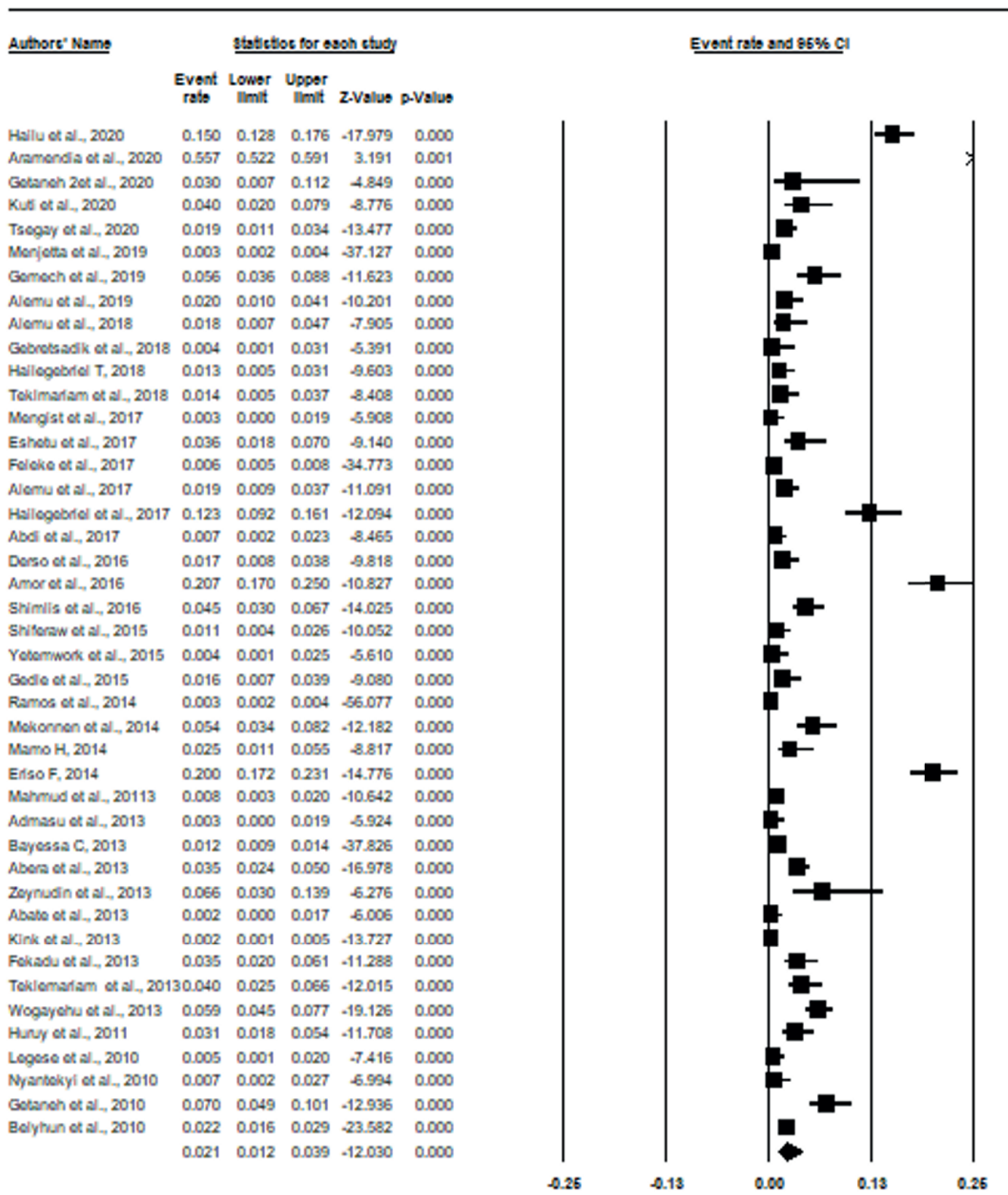

Fig. 2. Front plot of the prevalence of S. stercoralis in Ethiopia using random effect model. 
Table 2. The prevalence of S. stercoralis in different regions of Ethiopia between $2010-2020$.

\begin{tabular}{|c|c|c|c|c|}
\hline Name of the region & $\begin{array}{l}\text { Number of } \\
\text { studies [N] }\end{array}$ & $\begin{array}{c}\text { Total examined } \\
{[\mathrm{N}]}\end{array}$ & $\begin{array}{l}\text { SS Positive } \\
\text { [N] }\end{array}$ & $\begin{array}{l}\text { Pooled prevalence } \\
(95 \% \mathrm{Cl})\end{array}$ \\
\hline Addis Ababa City & 2 & 706 & 62 & $8.78[6.85-11.17]$ \\
\hline Amhara & 16 & 8,570 & 732 & $8.54[7.96-9.16]$ \\
\hline Harari & 1 & 371 & 15 & $4.04[2.36-6.72]$ \\
\hline Oromia & 5 & 1319 & 20 & $1.52[0.96-2.38]$ \\
\hline SNNPR & 15 & 58,917 & 547 & $0.93[0.85-1.01]$ \\
\hline Tigray & 4 & 9,076 & 61 & $0.67[0.52-0.86]$ \\
\hline Total & 43 & 78,959 & 1,437 & $1.82[1.73-1.92]$ \\
\hline
\end{tabular}

*SS = Strongyloides stercoralis

heterogeneity was high $\left(Q=1808.2, I^{2}=99.7 \%, P<0.001\right)$ (Fig 4). In this review, $37(86.05 \%)$ of the studies were conducted by DSM, KK, FECT or a combination these methods. High prevalence $44.02 \%$ rate of $S$. stercoralis infection was recorded with a combination of FECT, BCT and PCR and followed by $20 \%$ with only BCT and $15.05 \%$ S. stercoralis prevalence with a combining FECT, STST, BCT, and culture diagnostic methods (Table 3). A low prevalence of $S$. stercoralis was traced $0.26 \%, 0.31 \%$, and $1.20 \%$ by the respective KK, DSM and FECTs (Table 3).

The pooled prevalence of $S$. stercoralis across different diagnostic methods was $3.7 \%(95 \% \mathrm{Cl}: 1.10-11.70)$ using random effect analysis. The heterogeneity was high $\left(Q=4376.6, I^{2}=99.8 \%, P\right.$ $<0.001$ ) (Fig 5).

\section{Discussion}

The true prevalence estimation of Strongyloides infection in Ethiopia is generally difficult due to application of very low sensitive diagnostic techniques and the presence of a few studies conducted with high sensitive diagnostic approaches so far in the country. The most widely used methods for the diagnosis of helminthic infections include DSM, FECT and KK. These methods are less sensitive for the detection of Strongyloides infection (Siddiqui et al., 2001; Buonfrate et al., 2015). Similarly, in this review, the authors on Strongyloides infection have clearly demonstrated that surveys conducted with these three methods mentioned above might provide untrustworthy prevalence reports among the peoples of Ethiopia.

\section{Funnel Plot of Precision by Logit event rate}

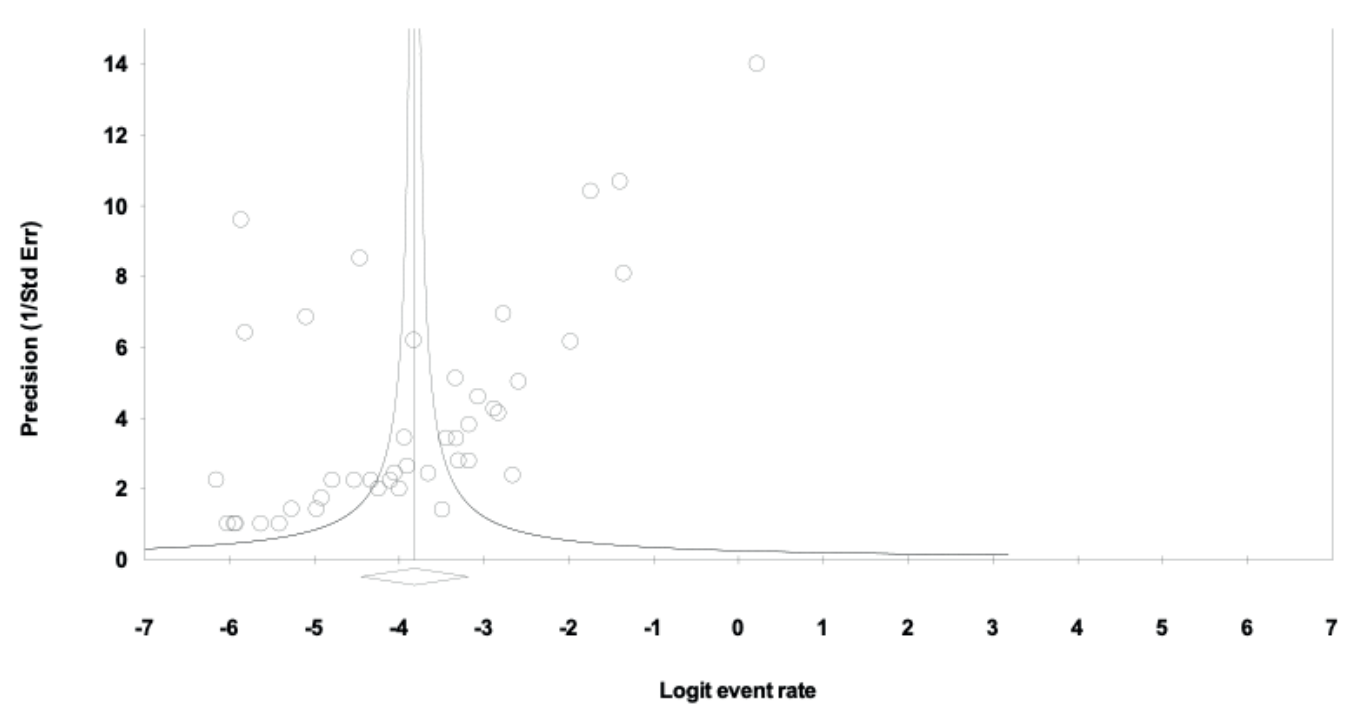

Fig. 3. Detection of the bias of the studies conducted using publication bias model. 


\begin{tabular}{|c|c|c|c|c|c|c|}
\hline \multirow[t]{2}{*}{ Name of the Region } & \multirow[t]{2}{*}{ Number of studies } & \multicolumn{4}{|c|}{ Statistics for each study } & \multirow{2}{*}{$\begin{array}{l}\text { Event rate } \\
\text { and } 95 \% \mathrm{C}\end{array}$} \\
\hline & & $\begin{array}{c}\text { Event } \\
\text { rate }\end{array}$ & $\begin{array}{l}\text { Lower } \\
\text { limit }\end{array}$ & $\begin{array}{l}\text { Upper } \\
\text { limit Z-Value }\end{array}$ & -Value & \\
\hline Addis Ababa City & 2 & 0.088 & 0.069 & $90.111-17.602$ & 0.000 & \\
\hline Amhara & 16 & 0.085 & 0.080 & $0.092-61.347$ & 0.000 & \\
\hline Harari & 1 & 0.040 & 0.025 & $50.066-12.015$ & 0.000 & \\
\hline Oromia & 5 & 0.015 & 0.010 & $0.023-18.523$ & 0.000 & \\
\hline SNNPR & 15 & 0.009 & 0.009 & 9 0.010108 .716 & 0.000 & \\
\hline \multirow[t]{2}{*}{ Tigray } & 4 & 0.007 & 0.005 & $\begin{array}{ll}5 & 0.009-38.887\end{array}$ & 0.000 & \\
\hline & & 0.026 & 0.008 & $\begin{array}{lll}3 & 0.082 & -5.912\end{array}$ & 0.000 & \\
\hline
\end{tabular}

Fig 4. Frost plot of the prevalence of $S$. stercoralis across regions using random effect model.

The low distribution of Strongyloides infection in the current review might be explained by the fact that low sensitive diagnostic methods and small quantity (about $2 \mathrm{mg}$ ) of stool samples that have been used in DSM. For instance, single stool examined by DSM can give $70 \%$ S. stercoralis false negativity (Siddiqui et al., 2001; Mirdha et al., 2009). The intermittent excretion nature (Burke et al., 1978) and low-intensity chronic infection of S. stercoralis (Schar et al., 2013) might also affect the true prevalence. In Ethiopia, highly sensitive diagnostic methods are not employed for Strongyloides infection and this might be due to their high cost and lack of aware- ness. As a result, almost all health institutions are still using low sensitive diagnostic methods for the clinical diagnosis of Strongyloides infection. This leads to under diagnosis and under-report of S. stercoralis infection throughout the country.

On the other hand, spontaneous tube sedimentation technique (STST) (Tello et al., 2012), BCT, stool culture and molecular (e.g. PCR) methods are more sensitive than DSM and FECT for the diagnosis of Strongyloides infection (Schar et al., 2013; Buonfrate et al., 2015). A combination of these methods in a single stool sample examination provides a higher detection rate of $S$. stercoralis

Table 3. The prevalence of S. stercoralis using different diagnostic methods in Ethiopia between 2010 - 2020.

\begin{tabular}{lcccc}
\hline Diagnostic methods & $\begin{array}{c}\text { No of studies } \\
{[\mathrm{N}]}\end{array}$ & Total examined [N] & $\begin{array}{c}\text { S. stercoralis } \\
\text { Positive [N] }\end{array}$ & $\begin{array}{c}\text { Pooled prevalence } \\
(\mathbf{9 5 \%} \% \mathbf{C})\end{array}$ \\
\hline DSM & 3 & 46,254 & 145 & $0.31[0.26-0.36]$ \\
KK & 1 & 386 & 1 & $0.26[0.05-1.45]$ \\
FECT & 6 & 5,512 & 66 & $1.20[0.94-1.53]$ \\
BCT & 1 & 710 & 142 & $20.0[17.16-23.17] 1$ \\
DSM+KK & 2 & 494 & 10 & $2.02[1.10-3.68]$ \\
DSM+FECT & 20 & 20,535 & 296 & $1.44[1.28-1.61]$ \\
FECT+KK & 3 & 1,346 & 33 & $2.45[1.72-3.46]$ \\
DSM+FECT+KK & 2 & 955 & 24 & $2.51[1.65-3.77]$ \\
DSM+FECT+BCT & 1 & 384 & 27 & $7.03[4.88-10.04]$ \\
FECT+BCT+PCR & 2 & 1,188 & 523 & $44.02[41.18-46.90]$ \\
DSM+FECT+BCT+CULTURE & 1 & 351 & 43 & $12.25[9.22-16.09]$ \\
FECT+STST+BCT+CULTURE & 1 & 844 & 127 & $15.05[12.74-17.68]$ \\
\hline TOTAL & 43 & 78,959 & 1,437 & \\
\hline
\end{tabular}

${ }^{*} \mathrm{DSM}=$ Direct saline microscopy, FECT = Formol ether concentration technique, $\mathrm{KK}=$ Kato-Katz, STST = Spontaneous tube sedimentation technique, $\mathrm{BCT}=$ Baermann concentration technique, $\mathrm{PCR}=$ Polymerase chain reaction 


\begin{tabular}{|c|c|c|c|c|c|c|}
\hline \multirow[t]{2}{*}{ Diagnostic methods } & Number of studies & & Statistic & s for each study & & \multirow{2}{*}{$\begin{array}{l}\text { Event rate } \\
\text { and } 95 \% \mathrm{Cl}\end{array}$} \\
\hline & \multicolumn{5}{|c|}{$\begin{array}{l}\text { Event Lower Upper } \\
\text { rate limit limit Z-Value p-Value }\end{array}$} & \\
\hline DSM & 3 & 0.003 & 0.003 & $0.004-69.275$ & 0.000 & \\
\hline KK & 1 & 0.003 & 0.000 & $0.018 \quad-5.946$ & 0.000 & \\
\hline FECT & 6 & 0.012 & 0.009 & $0.015-35.636$ & 0.000 & \\
\hline BCT & 1 & 0.200 & 0.172 & $0.231-14.776$ & 0.000 & \\
\hline $\mathrm{DSM}+\mathrm{KK}$ & 2 & 0.020 & 0.011 & $0.037-12.143$ & 0.000 & \\
\hline DSM+FECT & 20 & 0.014 & 0.013 & $0.016-72.164$ & 0.000 & \\
\hline FECT+KK & 3 & 0.025 & 0.017 & $0.034-20.899$ & 0.000 & \\
\hline DSM+FECT+KK & 2 & 0.025 & 0.017 & $0.037-17.695$ & 0.000 & \\
\hline $\mathrm{DSM}+\mathrm{FECT}+\mathrm{BCT}$ & 1 & 0.070 & 0.049 & $0.101-12.936$ & 0.000 & \\
\hline $\mathrm{FECT}+\mathrm{BCT}+\mathrm{PCR}$ & 2 & 0.440 & 0.412 & $0.469-4.110$ & 0.000 & \\
\hline DSM+FECT+BCT+CULTURE & 1 & 0.123 & 0.092 & $0.161-12.094$ & 0.000 & \\
\hline \multirow[t]{2}{*}{ FECT+STST+BCT+CULTURE } & 1 & 0.150 & 0.128 & $0.176-17.979$ & 0.000 & \\
\hline & & 0.037 & 0.011 & $0.117 \quad-5.189$ & 0.000 & \\
\hline
\end{tabular}

Fig 5. Frost plot of $S$. stercoralis prevalence across different diagnostic methods using random effect model.

infection (Aranzazu et al., 2016; Albonico et al., 2016; Hailu et al., 2020). Reports in this review showed that those studies conducted using a combination of more than one method provided a better Strongyloides infection detection rate in Ethiopia (Abera et al., 2013; Aranzazu et al., 2016; Tamirat et al., 2017; Hailu et al., 2020). However, the sensitivity of these tests is not perfect since they were performed on a single faecal specimen which might underestimate the true prevalence. Therefore, there is a need to define a standard protocol in diagnostic methods being used to detect $S$. stercoralis in Ethiopia, especially in health institutions. Such priority recommendations might be important for elaboration of mapping of $S$. stercoralis infection in the country.

In the current review, the overall prevalence of human S. stercoralis infection in Ethiopia was low (1.82 \%). This result is lower than from previous reports $5.1 \%$ among human immune-viruses (HIV) infected cases reported previously globally (Ahmadpour et al., 2019), and $20 \%$ obtained from a large heterogeneity population and diagnostic methods in Latin America (Buonfrate et al., 2015). The high prevalence in the previous studies might be justified as both reviews include studies conducted by serological tests which are much more sensitive tests (Bisoffi et al., 2013). The study participants in the former study were also among HIV cases only. In addition, the variation in the ambient environment could favor the high prevalence of Strongyloides infection.

The prevalence of $S$. stercoralis infection was varied across re- gions of Ethiopia and relatively high prevalence of recorded in Addis Ababa City and Amhara Regional State. This difference might be due to the difference in the diagnostic methods used, sample size and the health status of study participants. For instance, all the participants in the Addis Ababa City were street dwellers and HIV cases who are highly vulnerable to $S$. stercoralis infection.

Generally, the low prevalence of $S$. stercoralis in Ethiopia is due to absence of better sensitive diagnostic methods and the low attention given to $S$. stercoralis infection, unlike other soil-transmitted helminthes by policy makers. Based on this review, we encourage scholars to further work on the standardization of $S$. stercoralis test protocols and to advise policy makers for the inclusion of $S$. stercoralis in soil-transmitted helminths prevention and control package.

Limitation of this review: We used only PubMed, Google Scholar and Science direct databases and Addis Ababa University databases as a source of articles which might be the limitation of the current review.

Conclusions: This review confirmed that the prevalence of $S$. stercoralis is under-reported in Ethiopia due to the use of low sensitive diagnostic methods. Diagnostic methods including culture, BCT or PCR or a combination these methods give better detection rate of $S$. stercoralis infection. Therefore, there is a need to revise the current diagnostic methods of Strongyloides infection to 
have better sensitive diagnostic methods in the country. Further research is also desirable to break the transmission cycle and reduce the impacts of Strongyloides infection in Ethiopia.

\section{Conflicts of Interest}

The authors declare that we have no conflict interests.

\section{Acknowledgments}

All the authors are acknowledged for their unreserved participation in articles collection, systematic analysis and meta-analysis activities.

\section{References}

Abate, A., Kibret, B., Bekalu, E., , Abera, S., Tekilu, T., Yalew, A., ENDRIS, M., WoRKu, L., TEKESTE, Z. (2013): Cross-sectional study on the prevalence of intestinal parasites and associated risk factors in Teda Health Centre, northwest Ethiopia. ISRN Parasitol, 2013: 2013. DOI:10.5402/2013/757451

AbDI, M., NibRet, E., MunSheA, A. (2017): Prevalence of intestinal helminthic infections and malnutrition among schoolchildren of the Zegie Peninsula,northwestern Ethiopia. J Infect Public Health, 10: 84 - 92. DOI: 10.1016/j.jiph.2016.02.009

Abera B., Alemu, G., Yimer, M., Herrador, Z. (2013): Epidemiology of soil-transmitted helminths, Schistosoma mansoni, and haematocrit values among schoolchildren in Ethiopia. J Infect Dev Ctries, 7(3): 253 - 260. DOI: 10.3855/jidc.2539

Abrescia, F.F., Falda, A., Caramaschi, G., ScalzinI, A., Gobbi, F., ANgheben, A., Gobbo, M., Schiavon, R., Rovere, P., Bisoffi, Z. (2009): Reemergence of strongyloidiasis, Northern Italy. Emerg Infect Dis, 15: 1531 - 1533. DOI: 10.3201/eid1509.090191

Adamu, H., Wegayehu, T., Petros, B. (2013): High prevalence of diarrhoegenic intestinal parasite infections among Non-ART HIV patients in Fitche Hospital, Ethiopia. PLOS ONE, 8(8): e72634. DOI: 10.1371/journal.pone.0072634

Ahmadpour, E., Ghanizadegan, M.A., Razavi, A., Kangarl, M., Seyfl, R., Shahdust, M., Yazdanian, A., Safarpour, H., Baghi, H.B., Zarean, M., HosseinI, S.A., Norouzi, R., Ebrahimi, M., Bangoura, B. (2019): Strongyloides stercoralis infection in human immunodeficiency virus-infected patients and related risk factors: A systematic review and meta-analysis. Transbound Emerg Dis, 66(6): 2233 - 2243. DOI: 10.1111/tbed.13310

Albonico, M., Becker, S.L., Odermatt, P., Angheben, A., Anselmi, M., Amor, A., Barda, B., Buonfrate, D., Cooper, P., Gétaz, L., Keiser, J., Khieu, V., Montresor, A., Muñoz, J., Requena-Méndez, A., Savioli, L., Speare, R., Steinmann, P., Lieshout, L.V., Utzinger, J., Bisoffi, Z., StrongNet Working Group. (2016): StrongNet: an international network to improve diagnostics and access to treatment for Strongyloidiasis control. PLoS Negl Trop Dis, 10(9): e0004898. DOI: 10.1371/journal.pntd.0004898
Aleka, Y., G/egziabher, S., Tamire, W., Birhane, M., Alemu, A. (2015): Prevalence and associated risk factors of intestinal parasitic infection among under five children in University of Gondar Hospital, Gondar, Northwest Ethiopia. Biomed Rese Ther, 2(8): 347 - 353. DOI: 10.7603/s40730-015-0020-2

Alemu, G., Abossie, A., Yohannes, Z. (2019): Current status of intestinal parasitic infections and associated factors among primary school children in Birbir town, Southern Ethiopia. BMC Infect Dis, 19: 270. DOI: 10.1186/s12879-019-3879-5

Alemu,G, Alelign, D, Abossie, A. (2018): Prevalence of opportunistic intestinal parasites and associated factors among HIV patients while receiving ART at Arba Minch Hospital in Southern Ethiopia: A cross-sectional study. Ethiop J Health Sci, 28: 2. DOI: 10.4314/ ejhs.v28i2.6

Amor, A., Esperanza, R., José, M.S., Arroyo, A., López-Quintana, B., Bayeh, A., Mulat, Y., Endalew, Y., Derejew, Z., Zimman, A., TAdesse, H., Wondemagegn, M., Echazú, A., Krolewieki, A.J., Aparicio, P., Herrador, Z., Melaku, A., Benito, A. (2016): High prevalence of Strongyloides stercoralis in school-aged children in a rural highland of north-western Ethiopia: the role of intensive diagnostic work-up. Parasit Vectors, 9: 617. DOI: 10.1186/s13071-016-1912-8

Aramendia, A.A., Anegagrie, M., Zewdie, D., Dacal, E., Saugar, J.M., Herrador, Z., Hailu, T., Yimer, M., Periago, M.V., Rodriguez, E., BENITO, A. (2020): Epidemiology of intestinal helminthiases in a rural community of Ethiopia: Is it time to expand control programs to include Strongyloides stercoralis and the entire community? PLoS Negl Trop Dis, 14(6): e0008315. DOI: 10.1371/journal. pntd. 0008315

BAYISSA, C. (2013): A Retrospective analysis of the results of a five-year (2005 - 2009) Parasitological examination for common intestinal parasites from Bale-Robe Health Center, Robe Town, Southeastern Ethiopia. ISRN Parasitol, 2013: 694731. DOI: 10.5402/2013/694731

Belyhun, Y., Medhin, G., Anberbir, A., Erko, B., Hanlon, C., Alem, A., Venn, A., Britton, J., Davey, G. (2010): Prevalence and risk factors for soil-transmitted helminth infection in mothers and their infants in Butajira, Ethiopia: a population based study. BMC Public Health, 10: 21. DOI: 10.1186/1471-2458-10-21

Bisoffi, Z., Buonfrate, D., Montresor, A., Requena-Méndez, A., Muñoz, J., Krolewiecki, A.J., Gotuzzo, E., Mena, M.A., ChiodinI, P.L., Anselmi, M., Moreira, J., Albonico, M. (2013): Strongyloides stercoralis: A plea for action. PLoS Negl Trop Dis, 7(5): e2214. DOI: 10.1371/journal.pntd.0002214

Buonfrate, D., Formenti, F, .Perandin, F., Bisoffi, Z. (2015). Novel approaches to the diagnosis of Strongyloides stercoralis infection. Clin Microbiol Infect, 21(6): 543 - 552. DOI: 10.1016/j. cmi.2015.04.001

Buonfrate, D., Mena, M., Angheben, A., Requena-mendez, A., Muñoz, J., Gobbi, F., Albonico, M., Gotuzzo, E., Bisoffi, Z. (2015): Prevalence of strongyloidiasis in Latin America: a systematic review of the literature. Epidemiol Infect, 143: 452 - 460. DOI: 10.1017/ S0950268814001563 
BURKE, J.A. (1978): Strongyloidiasis in childhood. Am J Dis Child, 132: 1130 - 1136. DOI: 10.1001/archpedi.1978.02120360086017 Campo-Polanco, L.F., Sarmiento, J.M.H., Mesa, M.A., Franco, C. J.V., LÓPEZ, L., Botero, L.E., BuILES, L.A.G. (2018): Strongyloidiasis in humans: diagnostic efficacy of four conventional methods and real-time polymerase chain reaction. Rev Soc Bras Med Trop, 51(4): 493 - 502. DOI: 10.1590/0037-8682-0055-2018

Derso, A., Nibret, E., Munshea, A. (2016): Prevalence of intestinal parasitic infections and associated risk factors among pregnant women attending antenatal care center at Felege Hiwot Referral Hospital, northwest Ethiopia. BMC Infect Dis, 16: 530. DOI 10.1186/s12879-016-1859-6

ERISO F. (2014): Epidemiological studies on Strongyloides stercoralis at Dilla District, Ethiopia. Afro-Egypt J Infect Endem Dis, 4(2): $69-79$

Eshetu, T., Sibhatu, G., Megiso, M., Abere, A., Baynes, H.W., Biadgo, B, Ayalew Jejaw Zeleke, A.J. (2017): Intestinal parasitosis and their associated factors among people living with HIV at University of Gondar Hospital, Northwest-Ethiopia. Ethiopian J Health Sci, 27(4): 411. DOI: 10.4314/ejhs.v27i4.12

Fantahun, Getaneh, F., Zeleke A.J.., Lemma, W., Tegegne, Y. (2020): Malaria parasitemia in febrile patients mono- and coinfected with soil-transmitted helminthiasis Attending Sanja Hospital, Northwest Ethiopia. J Parasitol Res, 2020: 9891870. DOI: 10.1155/2020/9891870

Fekadu, S., Taye, K.., Teshome, W., Asnake, S. (2013). Prevalence of parasitic infections in HIV-positive patients in southern Ethiopia: A cross-sectional study. J Infect Dev Ctries, 7(11): 868 - 872. DOI: 10.3855/jidc.2906

Feleke, D.G., Tarko, S., Hadush, H., Gebretsadik, D., Yosef ZenEBE, Y., SEID, A. (2017): Prevalence of intestinal parasitic infections in St. Marry Hospital, Axum, Northern Ethiopia: A Retrospective Study. J Trop Dis, 5: 2. DOI: 10.4172/2329-891X.1000235

Gebretsadik, D., Halleslasie, H., Feleke, D.G. (2018): Intestinal parasitosis among HIVIAIDS patients who are on anti-retroviral therapy in Kombolcha, North Central, Ethiopia: a cross-sectional study. BMC Res Notes, 11: 613. DOI: 10.1186/s13104-018-3726-6 Gedle, D., Gelaw, B., Muluye, D., Mesele, M. (2015): Prevalence of malnutrition and its associated factors among adult people living with HIVIAIDS receiving anti-retroviral therapy at Butajira Hospital, southern Ethiopia. BMC Nutrition, 1: 5. DOI: 10.1186/2055-0928$1-5$

Gemechu, A., Zerihun, Z., Mihret, T., Chimdo, J., Abayneh, A., Kaleb, D., Petros, S., Mohammed, E. (2019): Intestinal parasite infections and associated factors among inmates of Arba Minch prison, southern Ethiopia: cross sectional study. BMC Infect Dis, 19: 1086. DOI: 10.1186/s12879-019-4703-y

Getaneh, A., Medhin, G., Shimelis, T. (2010): Cryptosporidium and Strongyloides stercoralis infections among people with and without HIV infection and efficiency of diagnostic methods for Strongyloides in Yirgalem Hospital, southern Ethiopia. BMC Res Notes, 3 : 90. DOI: 10.1186/1756-0500-3-90
Hallegebriel, T. (2018): Undernutrition, intestinal parasitic infection and associated risk factors among selected primary school children in Bahir Dar, Ethiopia. BMC Infect Dis, 18: 394. DOI: 10.1186/ s12879-018-3306-3

Hallegebriel, T., Petros, B., Endeshaw, T. (2017): Evaluation of parasitological methods for the detection of Strongyloides stercoralis among individuals in selected health institutions In Addis Ababa, Ethiopia. Ethiop J Health Sci, 27(5): 515 - 522. DOI: 10.4314/ejhs. v27i5.10

Hallu, T., Nibret, E., Amor, A., Abaineh Munshea, A.,Anegagrie, A. (2020): Efficacy of single dose Ivermectin against Strongyloides stercoralis infection among primary school children in Amhara National Regional State. Infect Dis: Res Treat, 13: 1 - 6. DOI: 10.1177/1178633720932544

Huruy,K., Kassu, A., Mulu, A., Worku, N., Fetene, T., Gebretsadik, S., Biadglegne, F., Belayhun, Y., Muche, A., Gelaw, A., Anagaw, B., Yifru, S., Wondie, Y., Bekele, A., TiRuneh, M., Dieter, R., Moges, F. (2011): Intestinal parasitosis and shigellosis among diarrheal patients in Gondar teaching hospital, northwest Ethiopia. BMC Res Notes, 4: 472. DOI: 10.1186/1756-0500-4-472

King, J.D., Endeshaw, T., Escher, E., Alemtaye, G., Melaku, S, Woyneshet, G., Abebe, W., Mitku, A., Berhanu, M., Tesfaye, T., Mulat, Z., Demelash, G., Zerihun, T., Mosher, A.W., Odermatt, P., Utzinger, J., Marti, H., Ngondi, J., Hopkins, D.R., Emerson, P.M. (2013): Intestinal parasite prevalence in an area of Ethiopia after implementing the SAFE strategy, enhanced outreach services, and health extension program. PLoS Negl Trop Dis, 7(6): e2223. DOI: 10.1371/journal.pntd.0002223

Kuti, K.A., NuR, R.A., Dunka, G.M., Kerbo, A.A., Roba, A.E. (2020): Predictors of intestinal parasitic infection among food handlers working in Madda Walabu University, Ethiopia: a cross-sectional study. Interdiscip Perspect Infect Dis, 2020: 9321348. DOI.10.1155/2020/9321348

Legese, L., ERKo, B., Hallu, A. (2010): Current status of intestinal Schistosomiasis and soil transmitted helminthiasis among primary school children in Adwa Town, Northern Ethiopia. Ethiop J Health Dev, 24(3): 191 - 197. DOI: 10.4314/ejhd.v24i3.68384

Mahmud, M.A., Spigt, M., Bezabih, A.M., López Pavon, I., Dinant, G-J., VELASCO,R.B. (2013): Risk factors for intestinal parasitosis, anaemia, and malnutrition among school children in Ethiopia. Pathog Glob Health, 107(2): 58 - 65. DOI: 10.1179/2047773213Y.0000000074 Mamo, H. (2014): Intestinal parasitic infections among prison inmates and tobacco farm workers in Shewa Robit, North-Central Ethiopia. PLoS ONE, 9(6): e99559. DOI: 10.1371/journal. pone. 0099559

MeKonnen, B., ERKo, B., Legese, M. (2014): Prevalence of intestinal parasitic infections and related risk factors among street dwellers in Addis Ababa, Ethiopia. J Trop Dis, 2: 2. DOI: 10.4172/2329891X.1000132

Mengist, H.M., Olifan Zewdie, O., Adugna Belew, A. (2017): Intestinal helminthic infection and anemia among pregnant women attending ante-natal care (ANC) in East Wollega, Oromia, Ethiopia. 
BMC Res Notes, 10: 440. DOI: 10.1186/s13104-017-2770-y

Menjetta, T., Simion, T., Anjulo, W., Ayele, A., Halle, M., Tafesse, T., Asnake, S. (2019): Prevalence of intestinal parasitic infections in Hawassa University students' clinic, Southern Ethiopia: a 10year retrospective study. BMC Res Notes, 12: 702. DOI: 10.1186/ s13104-019-4747-5

MIRDHA, B. (2009): Human strongyloidiasis: often brushed under the carpet. Trop Gastroenterol, 30(1): 1 - 4

Montes, M., SaWhney, C., BarRos, N. (2010): Strongyloides stercoralis: there but not seen. Curr Opin Infect Dis, 23(5): 500 - 504. DOI: 10.1097/QCO.0b013e32833df718

Nielsen, P.B., Mojon, M. (1987): Improved diagnosis of strongyloides stercoralis by seven consecutive stool specimens. Zentralbl Bakteriol Mikrobiol Hyg A, 263: 616 - 618. DOI: 10.1016/s01766724(87)80207-9

Nyantekyl, L.A., Mengistu, L., Mulugeta, B., Konjit, T., Kebreten, M., Chanda, M., Berhanu, E. (2010): Intestinal parasitic infections among under-five children and maternal awareness about the infections in Shesha Kekele, Wondo Genet, Southern Ethiopia. Ethiop J Health Dev, 24(3): 185 - 190. DOI: 10.4314/ejhd.v24i3.68383 Olsen, A., van Lieshout, L., Mart, H., Polderman, T., Polman, K., Steinmann, P., Stothard, R., Thybo, S., Verweid, J.J., Magnussen, P. (2009): Strongyloidiasis-the most neglected of the neglected tropical diseases? Trans R Soc Trop Med Hyg, 103: 967 - 972. DOI: 10.1016/j.trstmh.2009.02.013

Ramos, J.M., Rodriguez-Valero, N., Tisiano, G., Fano, H., Yohannes, T., Gosa, A., Fruttero, E., Reyes, F., Górgolas, M. (2014): Different profile of intestinal protozoa and helminthic infections among patients with diarrhoea according to age attending a rural hospital in southern Ethiopia. Trop Biomed, 31(2): 392 - 397

Requena-Méndez, A., Chiodini, P., Bisoffi, Z., Buonfrate, D., Gotuzzo, E., MuÑoz, J. (2013): The laboratory diagnosis and follow up of Strongyloidiasis: a systematic review. PLoS Negl Trop Dis, 7(1): e2002. DOI: 10.1371/journal.pntd.0002002

SCHAD, G.A. (1989): Morphology and life history of Strongyloides stercoralis. In: GRove, D.I. (Ed) Strongyloidiasis a major roundworm infection of man. London: Taylor and Francis, pp. $85-104$ Schar, F., Trostdorf, U., Giardina,F., Khieu, V, Muth, S., Marti, H., Vounatsou,P., Odermatt, P. (2013): Strongyloides stercoralis: global distribution and risk factors. PLoS Negl Trop Dis, 7(7): e2288. DOI: 10.1371/journal.pntd.0002288

Shiferaw, M.B., MengIsTu, A.D. (2015): Helminthiasis: hookworm infection remains a public health problem in Dera District, South
Gondar, Ethiopia. PLoS ONE, 10(12): e0144588. DOI: 10.1371/ journal.pone.0144588

Shimelis, T., TASSACHEW, Y., LAMBiYo, T. (2016): Cryptosporidium and other intestinal parasitic infections among HIV patients in southern Ethiopia: significance of improved HIV-related care. Parasit Vectors, 9(1): 270. DOI 10.1186/s13071-016-1554-x

SIDDIQUI, A.A., BERK SL. (2001): Diagnosis of Strongyloides stercoralis infection. Clin Infect Dis, 33 (7): 1040 - 1047. DOI: 10.1086/322707

Teklemariam, D., Legesse, M., Degarege, A., Liang, S., Erko, B. (2018): Schistosoma mansoni and other intestinal parasitic infections in schoolchildren and vervet monkeys in Lake Ziway area, Ethiopia. BMC Res Notes, 11: 146. DOI: 10.1186/s13104-0183248-2

Teklemariam, Z., Abate, D., Mitiku, H., Dessie, Y. (2013): Prevalence of intestinal parasitic infection among HIV positive persons who are naive and on antiretroviral treatment in Hiwot Fana Specialized University Hospital, Eastern Ethiopia. Int Sch Res Notices, 2013(2): 324329. DOI: 10.1155/2013/324329

Tello, R., Terashima, A., Marcos, L.A., Machicado, J., Canales, M., Gotuzzo, E. (2012). Highly effective and inexpensive parasitological technique for diagnosis of intestinal parasites in developing countries: spontaneous sedimentation technique in tube. Int $\mathrm{J}$ Infect Dis, 16(6): e414 - 416

Terefe Y., Ross, K., Whiley, H. (2019:) Strongyloidiasis in Ethiopia: systematic review on risk factors, diagnosis, prevalence and clinical outcomes. Infect Dis Poverty, 8: 53. DOI: 10.1186/s40249019-0555-3

Tsegay, B., Yoseph, A., Beyene, H. (2020): Prevalence and factors associated with intestinal parasites among children of age 6 to 59 months in, Boricha district, South Ethiopia, in 2018. BMC Pediatr., 20: 28. DOI: 10.1186/s12887-020-1935-3

Wogayehu, T., Tsalla, T., Belete, S., Teklu, T. (2013): Prevalence of intestinal parasitic infections among highland and lowland dwellers in Gamo area, South Ethiopia. BMC Public Health, 13: 151. DOI: 10.1186/1471-2458-13-151

Zeynudin, A., Hemalatha, K., Kannan, S. (2013): Prevalence of opportunistic intestinal parasitic infection among HIV infected patients who are taking antiretroviral treatment at Jimma Health Center, Jimma, Ethiopia. Eur Rev Med Pharmacol Sci, 17: 513 $-516$ 